\title{
Sonographic Placental Thickness Measurement: A Trustworthy Saviour for Foetal Age Estimation in Uncomplicated Pregnancy
}

\section{ABSTRACT}

Introduction: Placenta is a foeto-maternal organ playing a crucial role in endocrine, immunological, excretory, respiratory, and nutritional functions for the foetus. Gestational age estimation is usually based on the last menstrual period and ultrasonography. Many females having irregular menstruation present with unreliable last menstrual period and hence ultrasonography comes into play for correctly estimating the gestation. Various sonologically derived foetal parameters used for gestational age estimation are Crown Rump Length $(\mathrm{CRL})$, Biparietal Diameter (BPD), Head Circumference (HC), and Abdominal Circumference (AC). The placental thickness measurement shows a direct correlation with the gestational age of the foetus till certain weeks of pregnancy, therefore could be utilised as a new and simple parameter in scenarios like term pregnancy where other parameters are unreliable.

Aim: To study the relationship between sonographic placental thickness measurement and gestational age of the foetus and also correlating other biometric parameters i.e., BPD, AC, femur length with placental thickness.

Materials and Methods: The present study was a crosssectional study conducted in the Department of Radiodiagnosis, in collaboration with the Department of Obstetrics and Gynaecology, Rohilkhand Medical College and Hospital, Bareilly, Uttar Pradesh, India. Sample size constituted of 200 normal antenatal women in whom the placental thickness for various gestational age and correlation between placental thickness measurement with the gestational age of the foetus was done. Analysis of the relationship between placental thickness and other foetal parameters like BPD, femur length and AC was also assessed using Pearson correlation coefficient.

Results: Placental thickness measurements for gestational age 11-39 weeks were calculated; it gradually increased from $11.29 \mathrm{~mm}$ (mean) at 11 weeks to 35 millimeters ( $\mathrm{mm}$ ) (mean) at 39 weeks of gestation. Correlation coefficient was 0.9685 and $p$-value $<0.01$. Also, there was a significant positive correlation of placental thickness with other foetal biometry parameters like BPD, femur length and AC $(p<0.001)$.

Conclusion: The measurement of placental thickness can become a key parameter for estimation of foetal age especially in cases where the exact duration of pregnancy is not known. It can also facilitate the detection of abnormal placental thickness associated with maternal and foetal complications in the early stages.

\section{INTRODUCTION}

The placenta is a foeto-maternal organ which is partially formed by embryonic structures and partly from decidua. It plays a crucial role in endocrine, immunological, excretory, respiratory, and nutritional functions for the foetus. It prohibits microorganisms transfer from the maternal circulation to foetal circulation [1]. The mature placenta weighs about 450 grams, is discoid, with a diameter of 15 to $20 \mathrm{~cm}$ [2]. The placenta is smooth on its foetal surface, while its uterine surface appears rough and lobulated. Each lobe is composed of several cotyledons, which is the basic unit of the placenta [3]. The foetoplacental-uterine circulation begins with deoxygenated blood pumped by the foetal heart through the ductus arteriosus into the descending aorta.

Donald I came up with localisation of the placenta by ultrasound in 1968 [4]. Ultrasound since previous times have proven to be a most sensitive, rapid and safe modality for placental localisation and diagnosing abnormalities of the placenta $[5,6]$. Sonographic placentography performed routinely has now-adays replaced old techniques like soft tissue radiography [7] and radioisotope scanning [8]. The most common indication for obstetric ultrasound is the estimation of gestational age. Sonography plays an essential role in guiding the management of patients where many clinical decisions depend on gestational age. Many women are not able to recall the last menstrual period and have irregular menstrual history, therefore in such cases; ultrasonography plays a pivotal role in accurately estimating the gestational age.

Various sonologically derived foetal parameters used for gestational age estimation are CRL, BPD, HC, and AC. BPD could not be reliably measured in the foetus during the term and premature rupture of the membrane. So, for conditions like this and others there appeared a need for another parameter for supplementing the gestational age estimation with minimal error. Placental thickness measurement can be utilised as a new and simple parameter for the estimation of gestational age. The placental thickness measurement is relatively simpler and contributes to the management of foetuses at risk [9]. Placental thickness can also be used as a gestational age indicator due to a linear increase in its thickness with advancing gestational age [10]. The diagnosis of abnormal pregnancy from normal can be done based on placental thickness [11].

The purpose of the present study was to assess the relationship of placental thickness with gestational age and the growth pattern of the placenta with advancing gestational age. Also, the correlation of other foetal biometric parameters with placental thickness was analysed. 


\section{MATERIALS AND METHODS}

This was a cross-sectional study, including 200 normal antenatal women. The study was done in the Department of Radiodiagnosis, collaborating with the Department of Obstetrics and Gynaecology, $\mathrm{RMCH}$, Bareilly, Uttar Pradesh, India, from November 2018 to October 2019. Ethical committee clearance was obtained from the Institutional Ethical Committee with no.-IEC/31/2018/SEP. Written informed consent was obtained from all the subjects. Each woman with known last menstrual period and of gestational age between 11 to 39 weeks which was estimated ultrasonographically by derived foetal parameters was examined. The obtained mean values of placental thickness were correlated with the gestational age. In present study, a total of 200 women were included and the sample size (n) was calculated by the formula:

$$
n=\frac{z^{2} \times \hat{p}(1-\hat{p})}{\varepsilon^{2}}
$$

Where, $\mathrm{z}$ is the $\mathrm{z}$ score, $\varepsilon$ is the margin of error, $\mathrm{n}$ is the population size and $\hat{p}$ is the population proportion. For this study, the value of $z$ was $1.96, \varepsilon$ (error) was 0.05 and $\hat{p}$ (population proportion) was 0.85 and the further sample calculated was 195.9216 which was rounded off and taken as 200.

Inclusion criteria: The antenatal women with no complications, comprising gestational ages from 11 weeks to 39 weeks, with known last menstrual period and regular menstruation were included.

Exclusion criteria: Patients diagnosed with hydrops foetalis, pregnancy induced hypertension, congenital anomalies, diabetes mellitus, intrauterine growth retardation, twin pregnancy, polyhydramnios and oligohydramnios. Placenta with pathological and morphological variations like placenta accreta, percreta, lobed placenta, succenturiate lobe, circumvallate placenta and placenta with variations in the insertion of umbilical cord-like marginal or battledore placenta and velamentous cord insertion, also, placenta with poor visualisation of the cord insertion site were excluded.

Methods: An ultrasound scan was done in the supine position using a real-time B-mode curvilinear array "GE LOGIC V5" ultrasound machine equipped with a $3.5 \mathrm{MHz}$ transducer. Measurement of the placental thickness (in mm) was done at the level of the cord insertion site [12].

The cord insertion site of sonography appears as V-shape hypoechoic areas near the chorionic plate in the thickest portion of the placenta. It could also be sometimes seen as linear echoes perpendicular to the placental surface. The placental thickness was calculated at or near the mid-placental portion from the placental myometrial interface to the echogenic chorionic plate. Myometrium and subplacental veins were excluded while obtaining measurements. The conventional biometric measurements like BPD, AC and femur length were also obtained along with placental thickness.

On an axial image foetal head BPD was measured from outer to inner margin of the calvarium at the level of the paired thalami, third ventricle, and cavum septum pellucidum using callipers. AC was measured at the level of the stomach and intrahepatic portion of the umbilical vein on an axial image of the foetal abdomen. The outer surface of the skin around the abdomen was included while measurement was done using elliptical callipers. The femur length measurement was done by placing the callipers on either ends of the ossified diaphysis. CRL measurement using callipers and calculations using Hadlock tables were utilised for obtaining the gestational age in the first trimester from 11 to 13 weeks of pregnancy [13].

Representative cases for acquiring data i.e., BPD, femur length, AC and placental thickness with cord insertion site (solid arrows) on sonography are shown in [Table/Fig-1,2].

In the second and third trimesters from 14 to 39 weeks of pregnancy gestational age is determined by combined foetal measurements of BPD, AC and femur length [14]. Gestational age was calculated by the ultrasound machine based on Hadlock tables [13,15-17].

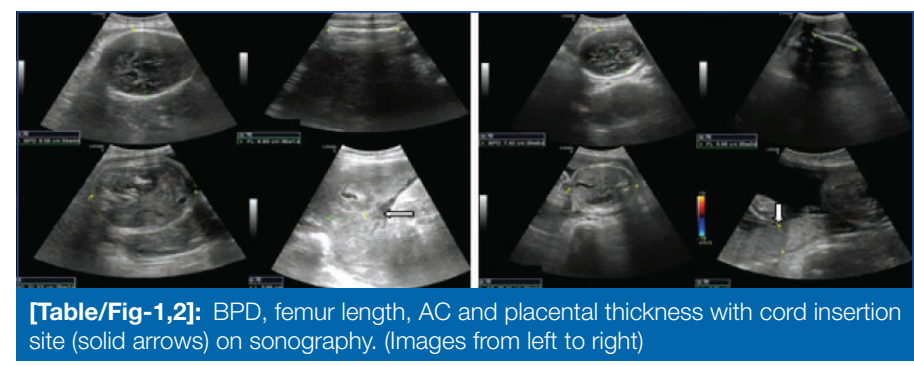

Measurements were acquired only once for each subject during the entire study.

The study analyses the correlation of placental thickness (in mm) measured with advancing gestational age (in weeks). In this study after obtaining the mean placental thickness, it was correlated with calculated gestational age from 11 to 39 weeks.

\section{STATISTICAL ANALYSIS}

The measured BPD, AC, femur length were also correlated with placental thickness values along with gestational age using Karl Pearson's correlation using appropriate statistical methods for analysis and Statistical Package for the Social Sciences (SPSS) version 25 was used. Graphs and tables were generated using Microsoft Word and Excel.

\section{RESULTS}

A total of 200 normal antenatal women were recruited for the study between the gestation age of 11 to 39 weeks. The age of the study population ranged from 18 to 36 years. The mean \pm standard deviation of the age of the entire group of cases studied was $25.3 \pm 3.6$ years. The distribution of cases according to maternal age groups is presented in [Table/Fig-3].

\begin{tabular}{|l|c|c|}
\hline Age (years) & Number of cases & Percentage (\%) \\
\hline$<20$ & 6 & 3.0 \\
\hline $20-25$ & 103 & 51.5 \\
\hline $26-30$ & 70 & 35.0 \\
\hline$>30$ & 21 & 10.5 \\
\hline Total & 200 & 100 \\
\hline
\end{tabular}

The mean for each week of the gestational age was calculated and it was observed that the placental thickness gradually increased with the progressing gestational age. The mean placental thickness was $11.29 \mathrm{~mm}$ at 11 weeks of gestation and $35.0 \mathrm{~mm}$ at 39 weeks. Placental thickness nearly correlates with the gestational age in weeks from 11-35 weeks of gestation and thereafter it is lowered by approximately 1-4 mm up till 39 weeks of gestation. In this study, minimum, placental thickness observed was $11.29 \mathrm{~mm}$ and the maximum was $35.0 \mathrm{~mm}$. The mean placental thickness for each week of the gestational age along with the 95\% confidence interval is presented in [Table/Fig-4].

Growth of the placenta was seen in a linear correlation with the advancement of gestational age till 35 weeks of gestation and there is a fall in the growth of the placenta from 36 weeks of gestation onwards. It is statistically studied from a $95 \%$ confidence interval that gestational age can be accurately predicted from the placental thickness measurements. For every week of increase in gestational age, there is an average increase of placental thickness by $0.9268 \mathrm{~mm}$. The statistical data shows that placental thickness was directly related to gestational age with linear regression model yielding the following equation (1139 weeks) Placental thickness (in $\mathrm{mm})=0.9268 \times$ Gestational age (in weeks)+1.1395, $(r=0.9685), r=$ Pearson correlation coefficient depicted through [Table/Fig-5]. 


\begin{tabular}{|c|c|c|c|c|}
\hline $\begin{array}{l}\text { GA by USG } \\
\text { (in weeks) }\end{array}$ & $\begin{array}{l}\text { Number } \\
\text { of cases }\end{array}$ & $\begin{array}{l}\text { Percentage } \\
(\%)\end{array}$ & $\begin{array}{l}\text { Placental thickness } \\
(\mathrm{mm})(\text { Mean } \pm S D)\end{array}$ & $\begin{array}{c}\text { 95\% Confidence } \\
\text { interval (Lower-Upper) }\end{array}$ \\
\hline 11 & 7 & 3.50 & $11.29 \pm 0.70$ & $10.77-11.80$ \\
\hline 12 & 5 & 2.50 & $12.40 \pm 0.80$ & $11.70-13.10$ \\
\hline 13 & 4 & 2.00 & $13.00 \pm 0.71$ & $12.31-13.69$ \\
\hline 14 & 8 & 4.00 & $14.38 \pm 1.49$ & $13.34-15.41$ \\
\hline 15 & 8 & 4.00 & $15.38 \pm 1.32$ & $14.46-16.29$ \\
\hline 16 & 4 & 2.00 & $15.25 \pm 0.43$ & $14.83-15.67$ \\
\hline 17 & 6 & 3.00 & $16.33 \pm 1.11$ & $15.45-17.22$ \\
\hline 18 & 5 & 2.50 & $16.40 \pm 0.80$ & $15.70-17.10$ \\
\hline 19 & 7 & 3.50 & $18.86 \pm 0.99$ & $18.12-19.59$ \\
\hline 20 & 7 & 3.50 & $19.14 \pm 1.46$ & $18.06-20.22$ \\
\hline 21 & 11 & 5.50 & $20.64 \pm 0.88$ & $20.12-21.16$ \\
\hline 22 & 6 & 3.00 & $21.33 \pm 1.49$ & $20.14-22.53$ \\
\hline 23 & 8 & 4.00 & $22.63 \pm 0.99$ & 21.94-23.31 \\
\hline 24 & 7 & 3.50 & $24.57 \pm 0.90$ & $23.90-25.24$ \\
\hline 25 & 3 & 1.50 & $24.00 \pm 0.47$ & $23.47-24.53$ \\
\hline 26 & 6 & 3.00 & $24.67 \pm 1.49$ & $23.47-25.86$ \\
\hline 27 & 6 & 3.00 & $26.33 \pm 0.94$ & 25.58-27.09 \\
\hline 28 & 8 & 4.00 & $26.63 \pm 1.65$ & $25.48-27.77$ \\
\hline 29 & 7 & 3.50 & $28.29 \pm 1.58$ & $27.12-29.45$ \\
\hline 30 & 6 & 3.00 & $28.83 \pm 1.57$ & 27.58-30.09 \\
\hline 31 & 13 & 6.50 & $30.62 \pm 0.84$ & $30.16-31.07$ \\
\hline 32 & 11 & 5.50 & $31.82 \pm 1.11$ & $31.16-32.48$ \\
\hline 33 & 19 & 9.50 & $32.00 \pm 0.97$ & $31.56-32.44$ \\
\hline 34 & 8 & 4.00 & $33.00 \pm 1.41$ & $32.02-33.98$ \\
\hline 35 & 6 & 3.00 & $33.67 \pm 0.75$ & $33.07-34.26$ \\
\hline 36 & 5 & 2.50 & $33.60 \pm 1.02$ & $32.71-34.49$ \\
\hline 37 & 3 & 1.50 & $34.00 \pm 0.82$ & 33.80-34.92 \\
\hline 38 & 3 & 1.50 & $34.33 \pm 0.47$ & $33.80-34.87$ \\
\hline 39 & 3 & 1.50 & $35.00 \pm 0.82$ & 34.08- 35.92 \\
\hline Total & 200 & 100 & & \\
\hline
\end{tabular}

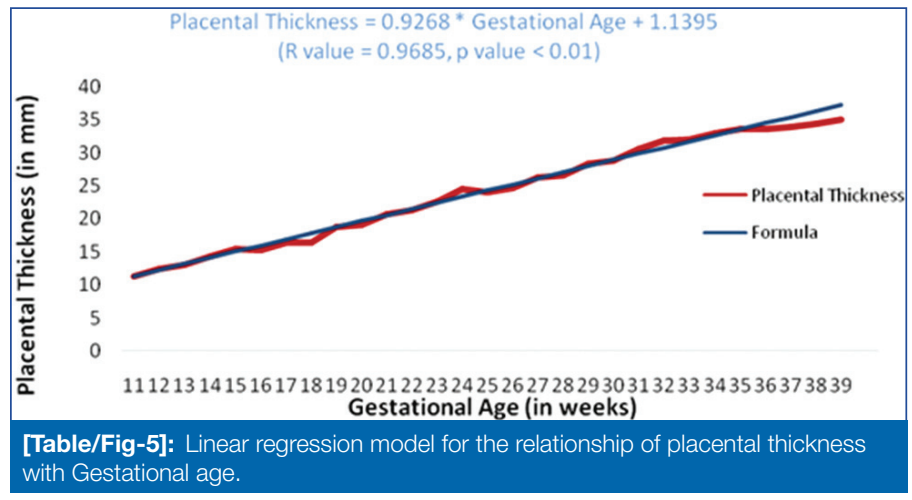

Linear regression analysis predicting foetal gestational age by sonography based on placental thickness was also studied and depicted in [Table/Fig-6]. Dependent variable is gestational age.

\begin{tabular}{|c|c|c|c|}
\hline Variable in the model & Beta coefficient & Standardised beta & $p$-value \\
\hline Constant & 1.035 & -- & $0.001^{\star \star \star}$ \\
\hline Thickness (mm) & 0.929 & 0.982 & $0.001^{\star \star \star}$ \\
\hline
\end{tabular}

The equation for prediction based on regression analysis is: $Y$ (Gestational Age) $=-0.4056+1.0457 \times$ Placental Thickness $(r=0.9681)$, by this equation, the gestational age can be predicted from the measurement of the placental thickness. The regression equation is Gestational Age $(Y)$ on Placental Thickness $(X)$ is shown in [Table/Fig-7].

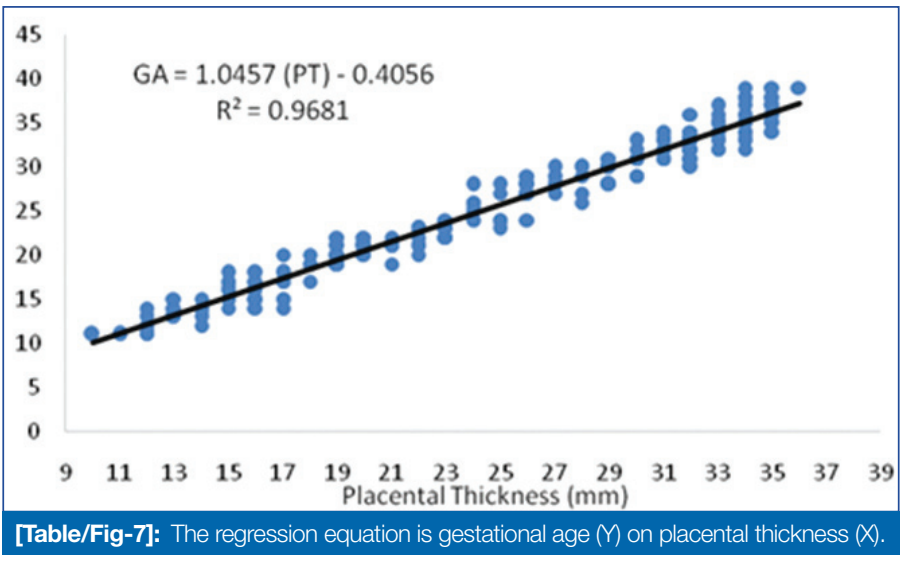

Placental thickness with foetal biometry like BPD, femur length, AC also showed a positive correlation.

[Table/Fig-8] depicts the determinants of BPD, AC, femur length and gestational age by the placental thickness. The productmoment correlation coefficient of placental thickness with BPD, AC, femur length and gestational age were 0.9733, 0.9770, 0.9754 and 0.9839 , respectively. The above correlation coefficients $(r)$ were statistically very highly significant $(p<0.001)$. The BPD was determined by the placental thickness as $94.73 \%$. Similarly, The AC, femur length and GA were determined as $95.46 \%, 95.14 \%$ and $96.81 \%$, respectively.

\begin{tabular}{|c|c|c|c|c|c|}
\hline Variables & R & $\mathrm{N}$ & Significance & R2 & $\%$ Determined \\
\hline PT X BPD & 0.9733 & 200 & $p<0.0001$ Significant & 0.9473 & 94.73 \\
\hline PT XAC & 0.9770 & 200 & $p<0.0001$ Significant & 0.9546 & 95.46 \\
\hline PTXFL & 0.9754 & 200 & $p<0.0001$ Significant & 0.9514 & 95.14 \\
\hline PT X GA & 0.9839 & 200 & $p<0.0001$ Significant & 0.9681 & 96.81 \\
\hline \multicolumn{6}{|c|}{$\begin{array}{l}\text { [Table/Fig-8]: BPD, FL, AC and GA showing positive correlation with placental } \\
\text { thickness. } \\
\text { BPD: Biparietal diameter; AC: Abdominal circumference; FL: Femur length; GA: Gestational age; } \\
\text { PT: Placental thickness }\end{array}$} \\
\hline
\end{tabular}

The growth variables estimated by placental thickness are BPD, AC, femur length with the help of the regression equations as shown in [Table/Fig-9-11].
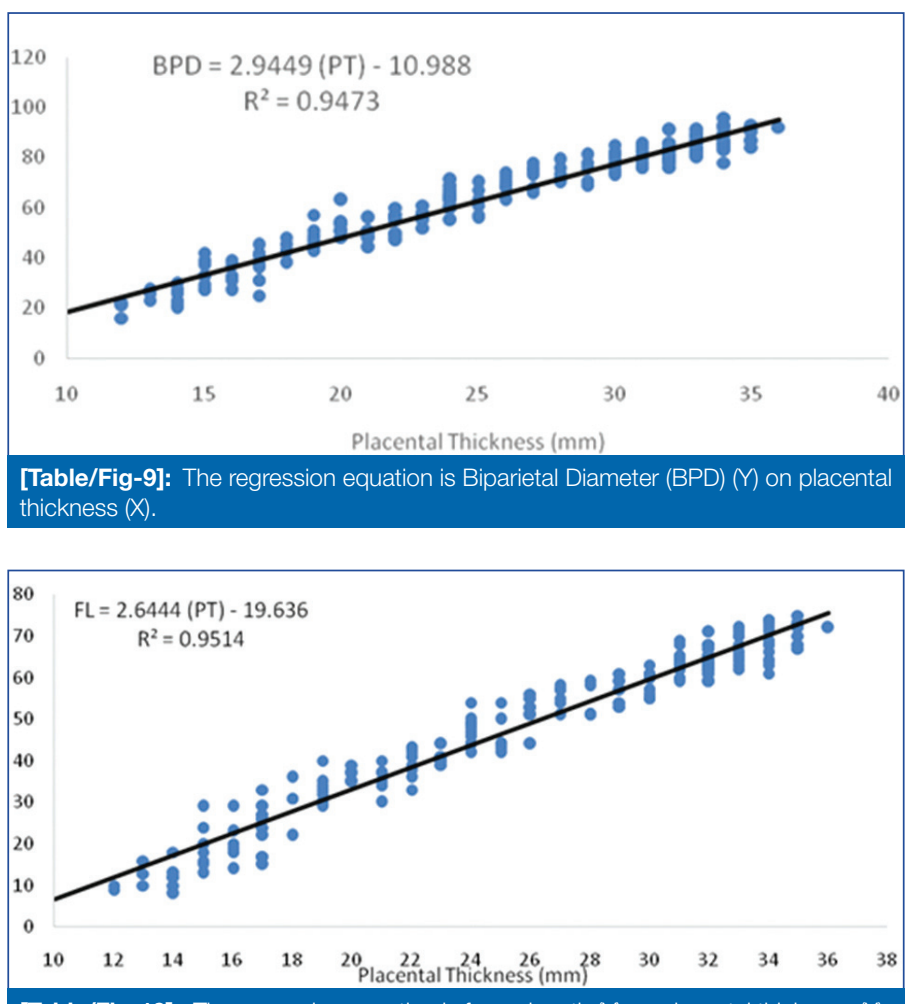
Table/Fig-10]: The regression equation is femur length $M$ on placental thickness $(X)$. 


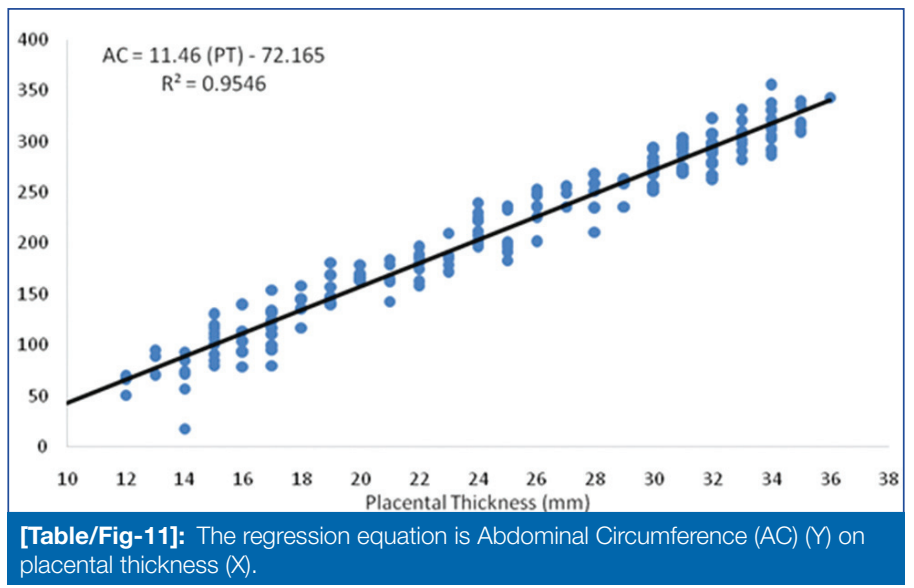

\section{DISCUSSION}

Since previous times, evaluation of the placenta has been routinely done for its position and timely diagnosis of various pathologies like placenta previa, premature placental abruption, etc., With the advancing ultrasonographic scan techniques, a detailed study of the placenta has been possible to know how placental morphology changes with the advancing gestational age.

In this study, 200 antenatal women with different gestational ages were studied for their placental thickness (in $\mathrm{mm}$ ) and growth pattern and further calculations for the mean values of placental thickness obtained for different gestational ages from 11-39 weeks showed comparable results with the study done by Mittal $\mathrm{P}$ et al., [Table/Fig-12] [10]. The correlation of the mean placental thickness measured in $\mathrm{mm}$ and the sonographic gestational age in weeks was evaluated.

Gottesfield KR and Hobbins JC in their study on 200 subjects, assessed that relationship of the placental thickness (in $\mathrm{mm}$ ) with ultrasonographic gestational age (in weeks) shows a positive correlation [6]. Similar results were obtained in this study where mean placental thickness has a positive correlation with the increasing gestational age.

Grannum et al., stated that there is an increase in placental thickness linearly until 33 weeks of gestation afterward it thins out [18]. Similarly, Nyberg DA and Finberg $\mathrm{HJ}$ also in their study stated that the placental thickness in $\mathrm{mm}$ parallels the gestational age [19]. Kobayashi M et al., described the correlation between placental thickness and gestational age in their study by placental growth curves and stated that the placental growth curve shows some flattening which begins just before the $35^{\text {th }}$ week of gestation [5]. Similarly in this study, it was evaluated that mean placental thickness increases with gestational age and shows a linear trend which paralleled with advancing gestational age (11-39 weeks) up to 35 weeks of gestation. An increase in the placental thickness from 35 weeks onwards falls gradually and lags behind the gestation age marginally by 1-4 mm. Present study results were also nearly consistent with the observation made by Mittal $P$ et al., [10].

Hellman LM et al., in their study also analysed that the placenta stops to grow after 37 weeks and the thickness becomes lesser in the last four weeks [20]. Hoddick WK et al., reviewed the sonograms performed on 200 singleton pregnancies and stated in their study that at no stage of pregnancy was the normal placenta greater than $4 \mathrm{~cm}$ in thickness [21]. In this study at no point with advancing gestation, the placental thickness was above $4 \mathrm{~cm}$. Elchalal $U$ et al., analysed sonographically thick placenta $\left(>4 \mathrm{~cm}\right.$ or $>90^{\text {th }}$ centile) is associated with increased perinatal mortality and morbidity like foetal anomalies, small-for-gestational age (SGA) or large-forgestational age (LGA) infants at term [22]. In present study, none of the women had a placental thickness of more than $4 \mathrm{~cm}$. Placental thickness $<10^{\text {th }}$ centile at 32 or 36 weeks could predict IUGR. Tongsong $T$ et al., identified that thick placenta in about $93.3 \%$ of

\begin{tabular}{|c|c|c|}
\hline $\begin{array}{l}\text { GA by USG } \\
\text { (in weeks) }\end{array}$ & $\begin{array}{l}\text { Mittal P et al., Placental } \\
\text { Thickness }(\mathrm{mm})(\text { Mean } \pm S D)\end{array}$ & $\begin{array}{l}\text { Present study Placental } \\
\text { Thickness }(\mathrm{mm})(\text { Mean } \pm \text { SD) }\end{array}$ \\
\hline 11 & $15.3 \pm 0.47$ & $11.29 \pm 0.70$ \\
\hline 12 & $15.93 \pm 4.4$ & $12.40 \pm 0.80$ \\
\hline 13 & $16.33 \pm 0.93$ & $13.00 \pm 0.71$ \\
\hline 14 & $16.72 \pm 2.3$ & $14.38 \pm 1.49$ \\
\hline 15 & $17.54 \pm 4.0$ & $15.38 \pm 1.32$ \\
\hline 16 & $18.62 \pm 1.1$ & $15.25 \pm 0.43$ \\
\hline 17 & $18.97 \pm 3.29$ & $16.33 \pm 1.11$ \\
\hline 18 & $19.3 \pm 1.1$ & $16.40 \pm 0.80$ \\
\hline 19 & $21.0 \pm 1.63$ & $18.86 \pm 0.99$ \\
\hline 20 & $21.5 \pm 0.49$ & $19.14 \pm 1.46$ \\
\hline 21 & $22.12 \pm 3.65$ & $20.64 \pm 0.88$ \\
\hline 22 & $22.8 \pm 1.61$ & $21.33 \pm 1.49$ \\
\hline 23 & $23.0 \pm 4.1$ & $22.63 \pm 0.99$ \\
\hline 24 & $24.6 \pm 1.44$ & $24.57 \pm 0.90$ \\
\hline 25 & $25.36 \pm 1.49$ & $24.00 \pm 0.47$ \\
\hline 26 & $26.2 \pm 1.35$ & $24.67 \pm 1.49$ \\
\hline 27 & $27.2 \pm 1.86$ & $26.33 \pm 0.94$ \\
\hline 28 & $28.5 \pm 3.42$ & $26.63 \pm 1.65$ \\
\hline 29 & $29.9 \pm 2.32$ & $28.29 \pm 1.58$ \\
\hline 30 & $30.5 \pm 3.05$ & $28.83 \pm 1.57$ \\
\hline 31 & $31.0 \pm 3.19$ & $30.62 \pm 0.84$ \\
\hline 32 & $31.8 \pm 4.49$ & $31.82 \pm 1.11$ \\
\hline 33 & $33.1 \pm 2.57$ & $32.00 \pm 0.97$ \\
\hline 34 & $33.9 \pm 4.83$ & $33.00 \pm 1.41$ \\
\hline 35 & $34.9 \pm 4.48$ & $33.67 \pm 0.75$ \\
\hline 36 & $35.3 \pm 3.5$ & $33.60 \pm 1.02$ \\
\hline 37 & $36.6 \pm 5.58$ & $34.00 \pm 0.82$ \\
\hline 38 & $37.1 \pm 2.36$ & $34.33 \pm 0.47$ \\
\hline 39 & $37.5 \pm 4.5$ & $35.00 \pm 0.82$ \\
\hline
\end{tabular}
gestational age [10]

women with cytomegalovirus infection [23]. This observation is of much help in antenatal management of suspected cases. Khanal UP et al., discussed in their prospective cross-sectional study that in normal pregnancy gestational age of a foetus can be predicted by measuring the placental thickness with a high confidence level (>95\% at all gestational age) [24].

In this study also, it was found that a positive correlation existed between placental thickness and gestational age, which was statistically assessed by Pearson correlation coefficient $(r=0.9685$ and $p$-value <0.01) and was also significant at a 95\% confidence interval. The regression equation was calculated to measure gestational age with a placental thickness which was $Y$ (Gestational age $)=-0.4056+1.0457 X$ placental thickness $(r=0.9681)$.

In the study done in the pregnant Nigerian women by Ohagwu CC et al., [25] in the second and third-trimester observation was made that placental thickness increased with gestational age in a nearly linear fashion. In the second and third trimester, a significant positive correlation was also seen between foetal parameters (BPD and AC) and placental thickness. This correlation strongly suggested that placental thickness can be utilised as a parameter for estimating gestational age. In our study, also placental thickness showed a significant correlation with other biometric parameters like BPD, FL and $A C$ throughout the gestational period.

In the present study also the regression equation was calculated to measure BPD, AC and femur length with placental thickness respectively as; $\mathrm{BPD}=2.9449$ (placental thickness)-10.988 $\left(R^{2}=0.9473\right), A C=11.46$ (placental thickness)-72.165 $\left(R^{2}=0.9546\right)$, $\mathrm{FL}=2.6444$ (placental thickness)-19.636 $\left(\mathrm{R}^{2}=0.9514\right) . \mathrm{BPD}, \mathrm{AC}$ and 
femur length are not accurate in determining gestational age in the third trimester and hence this study was conducted to show, that placental thickness could be utilised as an additional parameter in estimating gestational age accurately in the second and third trimester.

\section{Limitation(s)}

Accurate measurements of placental thickness are obtained on a perpendicular scan of the placenta. Hence, if images are scanned obliquely or near the periphery of the placenta, it may spuriously suggest thinning. A3D USG acquired placental volume measurement more accurately assesses placental size than placental thickness measurements. But, it is expensive and time-consuming. This study had a cross-sectional study design, which included observations on different individuals and the placental thickness was measured only once in each subject during the study. The sample size in this study was small for generating the nomogram of placental thickness for each gestational week and placental growth curves may be different for different population groups. As ultrasound measurements were obtained by a single observer and on the same machine, so there may be a chance for an observer bias (intra-observer variability) and instrumental bias.

\section{CONCLUSION(S)}

A linear and direct correlation was found between placental thickness and gestational age; hence placental thickness (in $\mathrm{mm}$ ) can be utilised as an important added parameter for estimating gestational age. It can also be correlated to other foetal biometric parameters like; $\mathrm{BPD}, \mathrm{AC}$ and femur length along with gestational age therefore, can minimise the discrepancy even in the late second and third trimester where other acquired foetal measurements show discrepancies. Further, the regression equation derived from the placental thickness measurements can also be of great help to determine the gestational age of the foetus. Attention to technical details and correct correlation of placental thickness with gestational age can facilitate the detection of abnormal placental thickness associated with maternal and foetal complications in the early stages.

\section{REFERENCES}

[1] GuimarãesFilho HA, da Costa LL, Júnior EA, Nardozza LM, Nowak PM, Moron $A F$, et al. Placenta: Angiogenesis and vascular assessment through threedimensional power Doppler ultrasonography. Archives of Gynaecol and Obstet. 2008;277(3):195.

[2] Hamilton WJ. Boyd JD. Trophoblast in human uteroplacental arteries. Nature. 1966;212:906
[3] Crawford JM. Vascular anatomy of human placenta. Am J Obstet Gynaecol. 1962;84:1543.

[4] Donald I. On launching a new diagnostic science. Am J obstet Gynecol. 1968;103:609-28.

[5] Kobayashi M, Hellman LM, Fillisti I. Placental localisation by ultrasound. Am J Obstet Gyanecol. 1970;106:279.

[6] Gottesfield KR, Thompson HE, Holmes JH, Taylor ES. Ultrasonic placentographyA new method of placenta localzation. Am J Obstet Gynecol. 1966;96:538.

[7] Dippel AL, Brown WH. Roentgen visualisation of the placenta by soft tissue technique. Am J Obstet Gynecol. 1940;40:986-94.

[8] Kohorn El, Walker RHS, Morrison J, Campbell S. Placental localization: A comparison between ultrasonic compound B scanning and radioisotope scanning. Am J Obstet Gynecol. 1969; 103(6):868-87.

[9] Jauniaux E. Placental ultrasonographic measurements: What can we learn and is it worth doing routinely? Ultrasound Obstet Gynaecol. 1992;2:241-42.

[10] Mittal P, Hooja N, Mehndiratta. Placental thickness- A sonographic parameter for estimating gestational age of the fetus. Ind J Radiollmag. 2002;12:553-54.

[11] Ghosh A, Tang MH, Lam YH Fung E, Chan V. Ultrasound measurement of the placental thickness to detect pregnancies affected by homozygous alpha thalassaemia-1. Lancet. 1994;344:988-89.

[12] Jauniaux E, Ramsay B, Campbell S. Ultrasonographic investigation of placental morphology and size during second trimester of pregnancy. Am $\mathrm{J}$ Obstet Gynaecol. 1994;170:130-37.

[13] Hadlock FP, Shah YP, Kanon DJ, Lindsey JV. Fetal crown-rump length Reevaluation of relation to menstrual age (5-18 weeks) with high-resolution realtime US. Radiology. 1992;182(2):501-05.

[14] Jeanty P. Fetal biometry. In: Fleischer AC, Romero R, Manning FA, Jeanty P, James AE, Eds. The principles and practice of ultrasonography in Obstetrics and Gynaecology, $4^{\text {th }}$ edition. Norwalk, Connecticut, Appleton and Lange. 1991;93.

[15] Hadlock FP, Deter RL, Harrist RB, Park SK. Fetalbiparietal diameter: A critical re-evaluation of the relation to menstrual age by means of real-time ultrasound. J of Ultrasound in Med. 1982;1(3):97-104.

[16] Hadlock FP, Deter RL, Harrist RB, Park SK. Fetal abdominal circumference as a predictor of menstrual age. Am J of Roentgenology. 1982;139(2):367-70.

[17] Hadlock FP, Harrist RB, Deter RL, Park SK. Fetal femur length as a predictor of menstrual age: Sonographically measured. Am $J$ of Roentgenology. 1982;138(5):875-78

[18] Granum PAT, Hobbins JC. The placenta. Radiol Clin North Am. 1982:20:353.

[19] Nyberg DA, Finberg HJ. The placenta, placental membranes and umbilical cord. In: Newburgh DA, Mahony BS Pretorius DH, Eds Diagnostic ultrasound of fetal anomalies. St Louis, Mosby Year book publishers 1990; 623-675.

[20] Hellman LM, Kobayashi M, Tolles W et al. Ultrasonic studies on the volumetric growth of human placenta. Am J Obstet Gynaecol. 1970;108:740.

[21] Hoddick WK, Mahoney BS, Callen FW, Filly RA. Placental thickness. J Ultrasound Med. 1985;4:479-82.

[22] Elchalal U, Ezra Y, Levi Y, Bar-Oz B, Yanai N, Intrator O, et al. Sonographically thick placenta: A marker for increased perinatal risk- A prospective crosssectional study. J of Cli Ultrasound. 2000;21:268-72.

[23] Tongsong T, Wanapirak C, Sirichotiyakue S. Placental thickness at mid pregnancy as a predictor of HbBarts disease. J on Prenatal Diagnosis. 1999;19:1027.

[24] Khanal UP, Paudel S, Lohani B. Ultrasonographic measurement of placental thickness during pregnancy as a parameter for estimating gestational age of the foetus. Nepalese Journal of Radiology. 2017;7(10):13-18.

[25] Ohagwu CC, Abu PO, Ezeokeke UO, Ugwa AC. Relationship between placenta thickness and growth parameters in normal Nigerian fetuses. African Journal of Biotechnology. 2009;8(2):133-38.

PARTICULARS OF CONTRIBUTORS:

1. Assistant Professor, Department of Radiodiagnosis, Rohilkhand Medical College and Hospital, Bareilly, Uttar Pradesh, India

2. Junior Resident, Department of Radiodiagnosis, Rohilkhand Medical College and Hospital, Bareilly, Uttar Pradesh, India.

3. Professor and Head, Department of Radiodiagnosis, Rohilkhand Medical College and Hospital, Bareilly, Uttar Pradesh, India.

4. Professor, Department of Obstetrics and Gynaecology, Rohilkhand Medical College and Hospital, Bareilly, Uttar Pradesh, India.

NAME, ADDRESS, E-MAIL ID OF THE CORRESPONDING AUTHOR:

Dr. Astha Nigam,

G-Block, Room No. 37, Rohilkhand Medical College and Hospital,

Bareilly-243006, Uttar Pradesh, India

E-mail: asthanigam1990@gmail.com

\section{AUTHOR DECLARATION:}

- Financial or Other Competing Interests: None

- Was Ethics Committee Approval obtained for this study? Yes

- Was informed consent obtained from the subjects involved in the study? Yes

- For any images presented appropriate consent has been obtained from the subjects. NA
PLAGIARISM CHECKING METHODS: [Jain Het al.]

- Plagiarism X-checker: Sep 21, 2020

- Manual Googling: Nov 12, 2020

- iThenticate Software: Dec 26, 2020 (16\%)
ETYMOLOGY: Author Origin Date of Peer Review: Oct 28, 2020

Date of Acceptance: Nov 16, 2020

Date of Publishing: Apr 01, 2021 